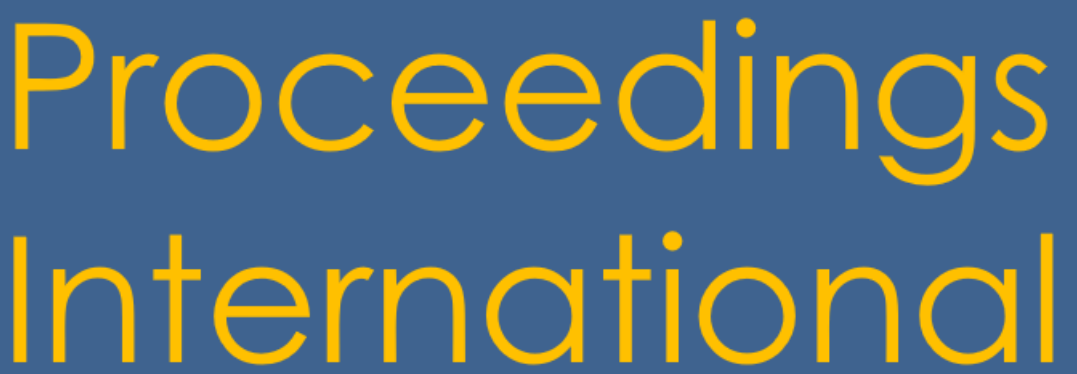

Volume 1, Issue 1, Pages 0032-0033

\title{
Microscopic investigations of the flotation tailings from Baia Mare Central Pond for highlighting the sulphides
}

\author{
D.-C. Mihaiescu ${ }^{1}$, A.-G. Vatui ${ }^{1}$, S.-N. Valsan ${ }^{1}$, F. Stoiciu ${ }^{1}$, A.N. Ghita ${ }^{1}$, M. Burada ${ }^{1}$, M. Ghita ${ }^{1}$ \\ 1 National R\&D Institute for Nonferrous and Rare Metals - IMNR, 102 Biruintei Blvd., 077145 Pantelimon-Ilfov, Romania \\ * Correspondence: danielcristian2000@yahoo.com
}

The strategy of the European Union regarding Raw Materials policy led to strategy called "Raw materials initiative" [1]. Thus, the use of waste dumps is encouraged in the sense of recovering the base metals through efficient eco-friendly technologies, according to the principles "fostering sustainable supply of raw materials from European sources, and boosting resource efficiency and promoting recycling" [2].

Microscopic investigations provide information on the minerals in which the elements of interest are present. In the case of the tailings from the Baia Mare Central Pond are followed the sulphides with base metal content $\mathrm{Cu}, \mathrm{Pb}, \mathrm{Zn}$. These can be distributed individually or in mineral associations, along with the gangue minerals. By microscopic methods (scanning electron microscopy- energy dispersive X-ray spectroscopy and optical microscopy) sulphides and other minerals from the initial material were observed, as well as metallurgical slags from ore processing. Keywords: sulphides; tailings; metals; microscopy; minerals.

\section{Funding}

This work was supported by a grant of the Romanian National Authority for Scientific Research and Innovation, CCCDI-UEFISCDI, project number 51/2018, COFUND-ERANET-ERAMIN-MINTECO2, within PNCDI III

\section{Acknowledgments}

Not applicable.

\section{Conflicts of Interest}

The authors declare no conflict of interest. 


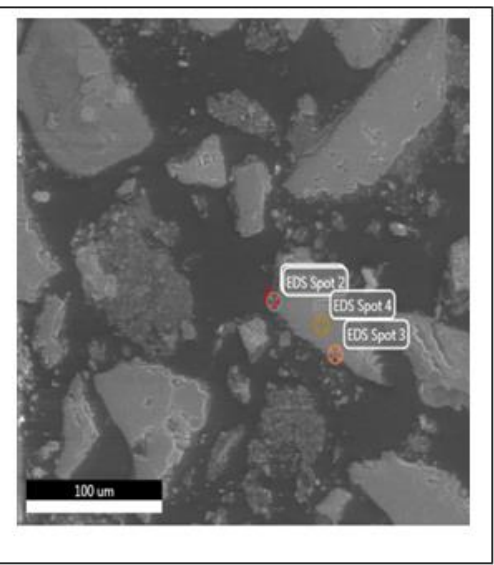

Figure 1. Scanning electron image, copper sulphide with slags and iron sulphide.
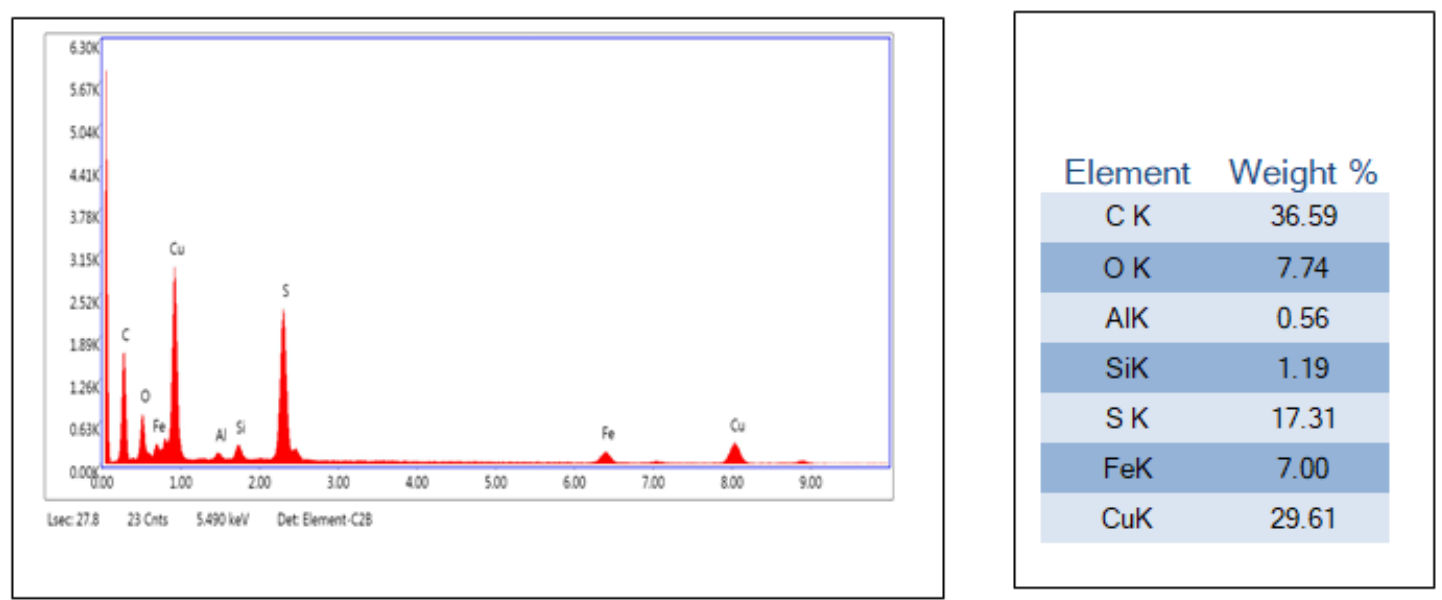

Figure 2. EDS analysis of Spot 3 marked in Figure 1.

Mineral of interest: copper sulphide.

\section{References}

1. https://ec.europa.eu/programmes/horizon2020/en /area/raw-materials.

Total Environ. 2016, 542, 629-641, https://doi.org/10.1016/j.scitotenv.2015.10.139

2. https://www.ima-europe.eu/content/raw-materialsinitiative.

3. Buzatu, A.; Dill, H.G.; Buzgar, N.; Damian, G.; Maftei, A.E.; Apopei, A.I. Efflorescent sulfates from Baia Sprie mining area (Romania)-Acid mine drainage and climatological approach.

4. Adinansyah, J.S.; Rosano, M.; Vink, S.; Keir, G. A framework for a sustainable approach to mine tailings management: Disposal strategies.

Clean Prod 2015, $108, \quad 1050-1062$ https://doi.org/10.1016/j.jclepro.2015.07.139.

(C) 2019 by the authors. This article is an open access article distributed under the terms and conditions of the Creative Commons Attribution (CC BY) license (http://creativecommons.org/licenses/by/4.0/). 